\title{
A Study on Entrapment Efficiency of Earthworms (Lumbricus rubellus) Extract in the Ethosomal Drug Delivery System
}

\author{
Sabrina Resky Pratiwi, Emilia Utomo, Hardyanti,Nur Ainiah, Dini Rusdayanti Putri \& Sartini
}

Faculty of Pharmacy, Hasanuddin University, Makassar, Indonesia

\begin{abstract}
Earthworms (Lumbricus rubellus) extract is known to contain bioactive protein as antibacterial compounds. One of the disadvantages of polar compounds is slow penetration into the skin layers which can be solved by formulating it in the form of ethosomal drug delivery system. The aims of this research was to find out information about ethanol concentration that provide the highest entrapment efficiency of the ethosome. Earthworms powder was macerated using $50 \%$ ethanol for 3 days. The extract was formulated into ethosome with variation of ethanol concentration that are $20 \%, 30 \%, 40 \%$, and $50 \%$, respectively. The measurement of entrapment efficiency was conducted by measuring the amount of active protein of earthworms extract that was entrapped in ethosome vesicles using spectrophotometer UV-Visible. The results showed that the entrapment efficiency was directly proportional to ethanol concentration in formula.
\end{abstract}

\section{Article History}

Received 18 June 2017

Accepted 19 August 2017

\section{Keyword}

Ethosome, ethanol concentration, entrapment efficiency, Lumbricus rubellus.

\section{Introduction}

Earthworms (Lumbricus rubellus L.) had been used as China traditional medicine and empirically used by people to treat thypoid fever caused by Salmonella thyposa and acne vulgaris caused by Propionibacterium acnes (Immanita, 2012; Sun, 2015). This treatment was supported by previous studies which showed that earthworms has antibacterial and antioxidant activity (Aldarraji, 2013; Mathur, 2011). Earthworm extract in concentration 7.5\% could inhibit the growth of Propionibacterium acnes and treat inflammation due to acne (Asmawati, 2016). Earthworm L. rubellus was made in a solid dosage form proved to have broad spectrum antimicrobial against Gram-positive bacteria S. aureus, Gram-negative bacteria E. coli, and fungi C. albicans (Damayanti et al., 2008). Besides, earthworms also contained phenolic compound which has antioxidant activity (Aldarraji, 2013).

The disadvantages of earthworms extract are having bad smell and slow absorption into skin layer caused by polar bioactive compounds. Previous research has conducted the formulation of earthworm extract in the gel preparation, but it wasnot able to cover the smell up (Asmawati, 2016). Another formula containing earthworm extract, maltodextrin, distilled 
water ( $2: 5: 50)$ was made by encapsulating extract in maltodextrin and tested for its antibacterial activity (Istiqomah, 2012).

The ethosome is a carrier of a kind of soft vesicle contained phospholipid, high concentrations of alcohol, and water (Tiwari, 2010 ; Patel, 2013). Ethosomal drug delivery system has many advantages such as good delivery of protein molecules, containing non toxic materials, increasing drug permeation into skin layers, and convenient to use.(Razavi, 2015; Sujatha, 2014). Good penetration of ethosome is caused by two mechanisms. Firstly ethanol takes a role as penetration enhancer which is penetrate into intercelluler lipid, increase lipid fluidity of cell membrane, and decrease multilayer lipid of cell membrane. Secondly, ethosome increases skin permeability so that it is easily permeated into inner layer of skin and release the drug (Parashar, 2013).

Entrapment efficiency is the most important thing in characterization study of ethosome formulation. It indicates the amount of drug or bioactive compounds which is entrapped in the vesicles. It will absolutely affect the amount of drug that reaches the target of therapy (Barupal,2010). In order to find out the highest entrapment efficiency of earthworms extract, the measurement of entrapment efficiency was done to four ethosome formula with variation of ethanol concentration (20\%,30\%, $40 \%$ and $50 \%$ ). The aims of this research was to find out information about ethanol concentration that provide the highest entrapment efficiency of the ethosome.

\section{Materials and Methods}

\section{Earthworm Preparation}

Dried earthworms (Lumbricus rubellus L.) that were used in this research obtained from Makassar, South Sulawesi, Indonesia.

\section{Extraction of Earthworms}

Earthworms extraction was done by using maceration method. A total of $500 \mathrm{~g}$ dried earthworms was macerated using $50 \%$ solvent ethanol for 3 days. The solvent was evaporated using rotary evaporator and continued with lyophilization to obtain viscous extract.

\section{Measurement of Total Protein Content of Earthworms Extract}

A total amount of $50 \mathrm{mg}$ extract was dissolved in distilled water to $10 \mathrm{ml}(5000 \mathrm{ppm})$. Taken $200 \mu \mathrm{l}$ of the solution and then added with reagent $\mathrm{C}$, incubated for 10 minutes and reagen $D$, incubate for 20 minutes. Distilled water was added up to $5 \mathrm{ml}$ (200 ppm). The absorbances were measured using spectrophotometer UV-Visible at $702 \mathrm{~nm}$.

\section{Preparation of Ethosomal Dispersion}

The composition of ethosome formula of earthworms extract is shown in Table 1.

Table 1. Composition of ethosome formula of earthworms extract

\begin{tabular}{|l|l|l|l|l|}
\hline \multirow{2}{*}{\multicolumn{1}{c|}{ Compositions }} & \multicolumn{4}{c|}{ Amount } \\
\cline { 2 - 5 } & \multicolumn{1}{|c|}{ F1 } & \multicolumn{1}{|c|}{ F2 } & \multicolumn{1}{c|}{ F3 } & F4 \\
\hline Earthworms extract & $0.5 \%$ & $0.5 \%$ & $0.5 \%$ & $0.5 \%$ \\
\hline Soya lecithin & $2 \%$ & $2 \%$ & $2 \%$ & $2 \%$ \\
\hline $96 \%$ Ethanol & $20 \%$ & $30 \%$ & $40 \%$ & $50 \%$ \\
\hline Propyleneglycol & $10 \%$ & $10 \%$ & $10 \%$ & $10 \%$ \\
\hline Distilled water up to & $100 \%$ & $100 \%$ & $100 \%$ & $100 \%$ \\
\hline
\end{tabular}


The ethosome was made using cold method. Earthworms extract was dissolved in ethanol and homogenized using magnetic stirrer for 5 minutes at $750 \mathrm{rpm}, 40^{\circ} \mathrm{C}$. After that, soya letichin was dispersed into the mixture. After 5 minutes, propyleneglycol was added into the mixture and homogenized for 5 minutes. Distilled water at $30^{\circ} \mathrm{C}$ was added at last. The size of ethosome vesicles was minimized by sonicating for 15 minutes.

\section{Determination of Entrapment Efficiency}

An amount of $1 \mathrm{ml}$ of ethosome was added to effendorf tube, then centrifugated for 2 hours at $13.000 \mathrm{rpm}, 4^{\circ} \mathrm{C}$. Taken $250 \mu \mathrm{l}$ of the supernatant, then was added with reagen $\mathrm{C}$, incubated for 10 minutes and reagen $D$, incubated for 20 minutes. Distilled water was added up to $5 \mathrm{ml}$. The absorbance was measured using spectrophotometer UV-Visible. Percentage of entrapment efficiency was calculated using the formula below:

$$
E E=\frac{\text { amountofentrappeddrug }}{\text { amountoftotaldrug }} \times 100 \%
$$

\section{Results and Discussion}

Entrapment efficiency is an important thing in the characterization study in ethosomal formulation. It indicates the amount of drug entrapped in the prepared vesicles (Verma, 2011). Because of that, it is expected that the higher the entrapment efficiency, the higher amount of drug that reaches target of therapy. In this study, there are four concentration of ethanol that was used that are F1 (20\%), F2 (30\%), F3 (40\%), and F4 (50\%).

The results showed the percentage of entrapment efficiency of F1, F2, F3, and F4 that are $35.56 \%, 30.45 \%, 59.16 \%$, and $72.58 \%$, respectively as shown in Figure 1.

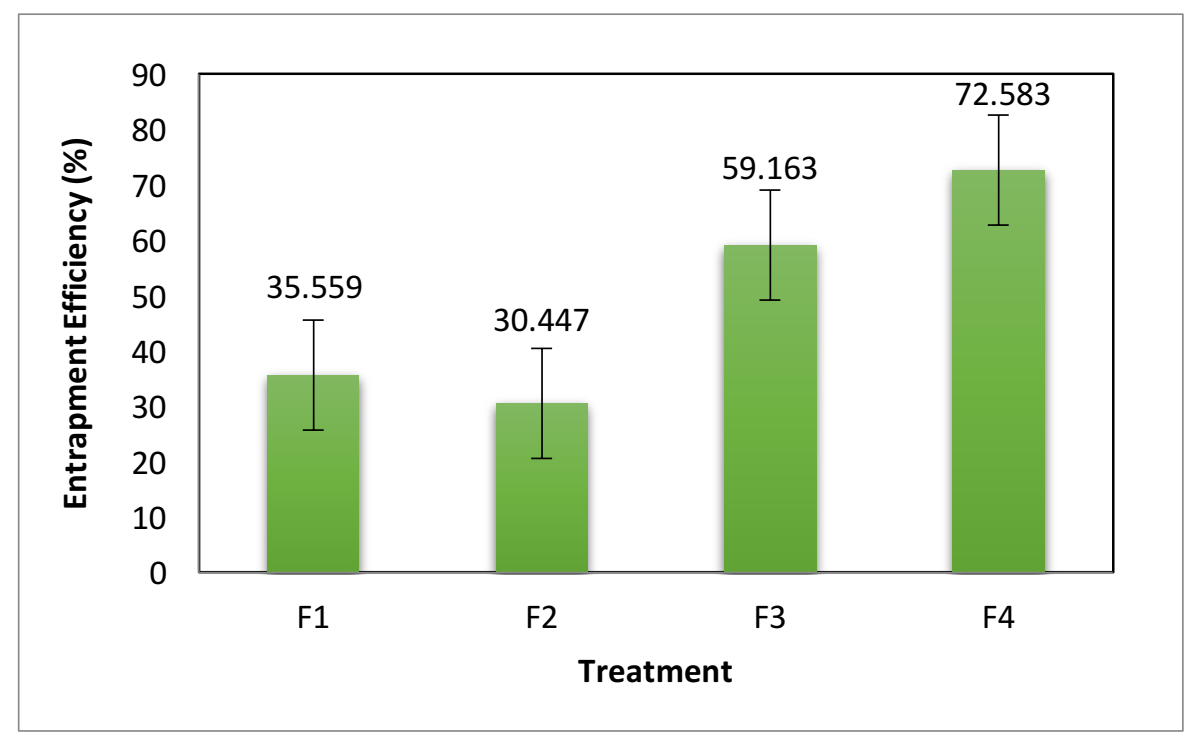

Figure 1. Entrapment Efficiency of Ethosome of Earthworms Extract

The results indicated that the entrapment efficiency was affected by ethanol concentration in formula. The highest entrapment efficiency was $72.58 \%$ given by F4 which containing $50 \%$ of ethanol. This is likely due to the solubility of extract in the ethosomal core was higher in F4 than other formulas. In this study, the entrapment efficiency of the formulation escalated along with the increasing of alcohol concentrations. Alcohol is a natural enhancer, which has the property to alter the skin permeability. However, transdermal permeability of 
ethosomal formulations was found to be higher compared to hydroalcoholic drug solution which indicates that alcohol is not the only one contributor to increase the skin permeability.

Several studies have investigated the possible mechanism of enhancing skin permeability by lipid vesicular system. Vesicles can interact with the stratum corneum lipids and alter the permeability, which facilitates penetration of drug across stratum corneum. Enhanced permeation of drug with ethosomal formulations could be caused by the combination effect of alcohol and lipid vesicular system (Chourasia,2011). According to Vijayan (2015), entrapment efficiency was affected by molar ratio of lecithin and ethanol. In addition, in the formulation of serratiopeptidase enzyme ethosome, the highest entrapment efficiency was $75.37 \%$ given by formula containing lecithin $5 \%(\mathrm{w} / \mathrm{w})$ : ethanol $20 \mathrm{ml}$, propyleneglycol $10 \mathrm{ml}$, active compound $0.05 \mathrm{mg}$ (Vijayan, 2015). Another previous research showed that there are two factors influencing the entrapment efficiency that are Soya Phosphatidyl Choline (SPC) and ethanol concentration. The amount of these materials influenced the entrapment of ketoprofen inside lipid vesicles in a positive way. It has been said the entrapment efficacy of $75-80 \%$ was provided by formula containing $30-40 \%$ of alcholo and $2,5-3 \%$ of SPC. While the lower efficacy was performed by formula containing $20-25 \%$ of alcohol and $1-2 \%$ of SPC (Chourasia,2011).

In addition, research about aceclofenac ethosome has shown that the highest and the lowest entrapment efficiency was given by formula containing $30 \%$ and $50 \%$ of ethano respectively. There was increase in percent entrapment efficiency was observed with an increase of ethanol concentration, but when ethanol concentration exceeded $30 \%$, a decrease in entrapment efficiency was observed. If ethanol concentration increased above $30 \%$ resulting into leakage of drug from fluidized bilayer of vesicles (Barupal, 2010). The obtained results of this research was in line with previous mentioned research which indicated that the higher the concentration of ethanol, the higher its entrapment efficiency. Besides, based on mechanism of drug entrapment in ethosome, hydrophilic drugs are entrapped in the aqueous core of lipid carrier while lipophilic drugs are retained in the nonpolar chain (Chourasia, 2011). So, earthworms extract which is hydrophilic was entrapped in the core of ehtosomes vesicle.

\section{Conclusion}

The highest percentage of entrapment efficiency of earthworms extract ethosome was $72.58 \%$ presented by formula containing earthworms extract $5 \%$, soya lecithin $2 \%$, propyleneglycol $10 \%$, and ethanol $50 \%$. The entrapment efficiency of the formulations was observed to increase along with the increasing concentration of alcohol.

\section{Acknowledgements}

This research was supported by The Ministry of Research, Technology and Higher Education of Republic of Indonesia for the Research Grant.

\section{References}

Aldarraji, Q.M., Halimoon, N. and Majid, N.M.2013. Antioxidant Activity and Total Phenolic Content of Earthworm Paste of Lumbricus rubellus (Red Worm) and Eudrilus eugenia (African Night Crawler). Journal of Entomology and Nematology. 5(3):33-37.

Asmawati and Pratiwi, S.R. 2016. Development of Earthworm (Lumbricus rubellus) Extract Formulation as Antiacne: Its Antiinflammatory and Antibacterial Activity. Research Grant Report. Universitas Hasanuddin. 
Barupal, A.K., Gupta. V., and Ramteke, S. 2010. Preparation and Characterization of Ethosomes for Topical delivery of Aceclofenac. Indian Journal of Pharmaceutical Sciences. 72(5):582586.

Damayanti, E., H. Julendra, \& A. Sofyan. 2008. Antimicrobial activity of earthworm meal Lumbricus rubellus and its potency as additive in poultry feed. J. Biosfera 25: 123-128

Immanita, S., Debora, K.., and Rochmanti, M. 2012. Effect of Earthworms (Lumbricus sp.) Extract Antibacterial Activity Against the Bacteria Salmonella Typhii. Folia Medica Indonesiana. 48(3):102-108.

Istiqomah, L., Herdian, H., Damayanti, E., Hayati, S.N., and Julendra, H. 2012. Inhibitory of Encapsulated Earthworm Extract (Lumbricus rubellus) on Pathogenic Bacteria in Vitro. Media Peternakan.35 (1): 1-8.

Mathur, A., Verma, S.K., Singh, S.K., Prakash, A., Prasad, G.B.K.S., and Dua, V.K. 2011. Antiinflammatory Activity of Earthworm Extracts. International Journal of Pharmaceutical Sciences and Research. 2(2):278-281.

Parashar, T., Sachan, R., Singh, V., Singh, G., Tyagi, S., Patel, C., and Gupta, A. 2013. Ethosomes: A Recent Vesicle of Transdermal Drug Delivery System. International Journal of Research and Development in Pharmacy and Life Sciences.2(2): 285-292.

Patel, A., Sharma, R.K., Trivedi, M., Shivaprakash, and Panicker, A. 2013. Ethosomes: A Novel Tool for Transdermal Drug Delivery. Research Journal of Pharmacy and Technology. 6 (8): 838-841.

Rajput, A., Shriwas, S., Dwivedi, S. and Dubey, R. 2016. Formulation And Evaluation Of Ethosomes Of Plumeria Indica Linn. Flowers. Advances in Pharmacology and Toxicology. 17(3): $45-48$

Razavi, H. and Janfaza, S. 2015. Ethosome: A Nanocarrier for Transdermal Drug Delivery. Journal of Paramedical Sciences. 6 (2): 38-43.

Sujatha, V., Vishnuvaravidyadhar, T., Parvathi., M., and Reddy, S. 2014. A Review on Transdermal Drug Delivery System by Ethosomes. PharmaTutor Magazine. 2 (11): 50-55.

Sun, Z. 2015. Earthworm as a Biopharmaceutical: From Traditional to Precise. European Journal of BioMedical Research. 1 (2): 28-35.

Tiwari, R.K., Chauhan, N.S., and Yogesh, H.S. 2010. Ethosomes: A Potential Carriers for Transdermal Drug Delivery. International Journal of Drug Development and Research. 2 (2): 448-452.

Verma,P.,Deshmukh,K.R., and Pandey,A. 2011. Entrapment Efficiency Study of Hydrophilic Molecule in Ethosomal Formulations. International Journal of Universal Pharmacy and Life Sciences. 1(3): 51-56.

Vijayan, V., Kumar, K.J., Muralidharan, S., and Parasuraman, S.Formulation and Characterization of Novel Ethanolic Carrier for Improves Penetration of Serratiopeptidase. Research \& Reviews: A Journal of Drug Formulation, Development and Production.2 (1): 1-6.

\section{To cite this article:}

Pratiwi, S.R., Utomo, E., Hardyanti, Ainiah, N., Putri, D.R. \& Sartini. 2017. A Study on Entrapment Efficiency of Earthworms (Lumbricus rubellus) Extract in the Ethosomal Drug Delivery System. International Journal of Applied Biology. 1(1) : 32- 36. 